\title{
PRINCIPLES OF AUTOMATION
}


Distributors for The United Kingdom and Eire:

CLEAVER-HUME PRESS LTD.

(Macmillan \& Co Ltd.)

10-15 St. Martin's Street, London, W.C. 2 


\section{PRINCIPLES OF}

AUTOMATION

WHAT A ROBOT CAN AND CANNOT DO

J. F. SCHUH

1965

Macmillan Education 
Translated from the Dutch by R. H. Bathgate, Knegsel, The Netherlands

Other editions of this book in Philips Technical Library in the Dutch, French, and German languages

This book contains xii +380 pages, 145 illustrations and 2 photos

U.D.C. No. 007:621.391.681.14-523.8

ISBN 978-1-349-81710-8 ISBN 978-1-349-81708-5 (eBook)

DOI 10.1007/978-1-349-81708-5

Original Dutch edition:

(C) N.V. Philips' Gloeilampenfabrieken, Eindhoven, The Netherlands, 1963

English edition:

(C) N.V. Philips' Gloeilampenfabrieken, Eindhoven, The Netherlands, 1965

Softcover reprint of the hardcover 1st edition 1965 978-0-333-06376-7

All rights reserved

No representation or warranty is given that the matter treated in this book is free from patent rights; nothing herein should be interpreted as granting by implication or otherwise, a licence under any patent rights 
The eternal mystery of the world is her comprehensibility.

(Albert Einstein, J. Franklin Inst. 221, (1936), p. 351)

\section{PREFACE}

This book is meant for all those who are interested in the theoretical and philosophical problems connected with the robot and has a two-fold purpose. In the first place it is intended to help those whose work brings them into contact with automata to design, construct or use them intelligently and creatively. In the second place it will discuss problems like "can an automaton really think?", "how much further can we perfect automata?", "can automata ever take over the world?", which appear to worry expert and layman alike to a certain extent.

It is a matter of common knowledge that since the end of the last world war we have succeeded - to name but two examples and with some exaggeration - in building huge factories (usually chemical) manned only by a couple of workmen and one engineer, and in building "electronic brains" which can perform calculations which were simply impossible before and can e.g. work out the pay packets for a big firm more cheaply and just as reliably as or even more reliably than an army of clerks.

The contemplation of these facts can give rise to a number of different reactions. In young (and not so young) men, it may arouse the desire to choose automation or computing as their profession. The author hopes that this book will help to give them the knowledge they need to realize this desire. Men who have already chosen this profession may wonder what are the practical limits of the automation, and what are the principles on which a better automaton can be constructed. The author hopes that this book will help to give them the insight needed to solve these problems. And all, specialist and layman alike, may find themselves asking with curiosity " $\mathrm{How}$ much truth is there in the name of "electronic brain" which we give to these computers?" and with a certain amount of trepidation "Are we not, like the Sorcerer's Apprentice, unleashing forces which we will be unable to control?" Unfortunately, there is still only one simple answer to these questions: "we're not quite sure". Those (like the author) whose work brings them more or less directly into contact with automata tend to take an optimistic view, while those who stand a little further off often tend to think, in the words of the Psalmist: "They have mouths, but they speak not; eyes have they, but they see not; they have ears, but they hear not; neither is there any breath in 
their mouths. They that make them shall become like them; yea, every one that trusteth in them" (Psalm 135, verses 16-18).

Let us take a closer look at the two examples of automata we have mentioned above. In the first, the chemical factory, we are no longer surprised to find machines to take the heavy work of lifting and pouring vast masses of chemicals off the workers' shoulders; but now we see machines which even relieve them of the task of measuring the temperature or the pressure, and turning the right knobs at the right moments. It is clear that if we were asked what the men in the old-fashioned factory were doing when carrying out these latter tasks, we might very well say that they were thinking, so that these machines which relieve them of the task of thinking have just as much right to be called "thinking machines" as the mechanized successor of the spinning wheel has the (unquestioned) right to be called a spinning machine. But while we see nothing wrong in saying that a spinning machine really spins, I think that most of us feel a certain resistance to saying that a "thinking machine" really thinks. This is because the thinking of these machines is so much more limited than our own that on second thoughts we doubt whether it really deserves the name - we may be fairly sure that a pressure stabilizer never thinks a pleasant or angry thought - or even less a thought about calculus. And on the other hand we feel that to equate what we know of the operation of a pressure stabilizer with thinking is to depreciate the value of our own thoughts, to insinuate that our own selves, which we feel to be so warm and living, are really just as cold and dead as that thing of metal and glass, if we could look deep enough.

If we turn to the electronic computer the situation becomes more puzzling and possibly more threatening. Not only does this machine perform a wider range of thought-like actions, including those which the human brain would find too time-consuming, although not too difficult, to perform in one lifetime - but its performances even resemble that of the human brain to a surprising and amazing extent when it is remembered that the electronic computer was designed as it is for reasons of convenience and not with the express purpose of resembling the brain. Here we feel an additional threat, though perhaps not so basic as the threat to our integrity mentioned above - which the electronic computer of course also provokes. We feel it quite possible that we could design computers of such complexity and power that they could free themselves of our yoke and dominate us. There is however no immediate danger of this happening at present; all automata so far made are quite docile.

In the introductory chapter we shall discuss the automaton in general terms, to introduce the reader to the subject matter of the later chapters, 
and to show how the more speculative questions given above have arisen even if we cannot answer them.

A glance at the contents of this book will make it clear to the reader that it is not without diffidence that the author brings this book before the public: who, indeed, could consider himself an expert in the whole range of subjects covered here? The author is therefore very grateful to the many friends who have given him help and advise whenever necessary.

In particular MY FATHER, who despite his advanced age has read through various parts of the book and made valuable comments especially on Appendix B, which deals with stochastics, a subject which is near to his heart, has contributed to ameliorate the original text at many places.

I also owe much thanks to DRs. DooRMAN, who read through the whole of Chapter II and made many corrections and suggestions for clarification; if this chapter is a success (as the author naturally hopes), it is largely thanks to him. Messrs E. AagaARD and J. T. KAGER contributed many useful improvements to chapter IV. Mr. G. J. VAN DER MARK made many suggestions which have led to a considerable improvement and clarification of the language of the original text and have led to the rewriting of many passages.

And last but not least, the author would like to thank Mr. R. H. BATHGATE, who took great pains to produce a faithful English translation in which he succeeded, in my opinion, extremely well and Mr. M. BREMMER who read through the English text and made many useful comments.

Eindhoven, December 1964

J. F. SCHUH 


\section{TABLE OF CONTENTS}

PREFACE .................. . . V

Chapter I: INTRODUCTION . . . . . . . . . . . . . . 1

1.1. What is an automaton? . . . . . . . . . . . 1

1.2. What is thinking? . . . . . . . . . . . . 2

1.3. Automata and nerve nets . . . . . . . . . . 5

1.4. Functions taking place in an automaton . . . . . . . 6

1.5. Signals and information . . . . . . . . . . . 7

1.6. The concept "signal content" . . . . . . . . . . . . . . 9

1.7. Types of signalling. . . . . . . . . . . . . . . 12

1.8. Something about nerve nets . . . . . . . . . . . . 13

1.9. The neuron regarded as a switching element . . . . . . 19

1.10. More about automata and nerve nets . . . . . . . . . 23

1.11. Chance, noise and interference . . . . . . . . . 25

1.12. Something about memories . . . . . . . . . . . . 29

1.13. Circuits and logic . . . . . . . . . . . . . . . 30

1.14. Example of a logical circuit. The binary adder. . . . . . 32

1.15. The signal transformer . . . . . . . . . . . . . . 38

1.16. The scientist as a "signal transformer" . . . . . . . . 40

1.17. What a robot can and cannot do . . . . . . . . . . 44

1.18. Something about the chess-playing machine . . . . . . 46

1.19. Conclusion . . . . . . . . . . . . . 48

Chapter II: ELEMENTS OF LOGIC . . . . . . . . . . . . . 49

2.1. Introductory remarks . . . . . . . . . . . . . . . . . . 49

2.2. Propositional logic . . . . . . . . . . . . . 52

2.21. Negation . . . . . . . . . . . . . 53

2.22. Disjunction . . . . . . . . . . . . . . 54

2.23. Conjunction . . . . . . . . . . . . . 55

2.24. Implication . . . . . . . . . . . . 56

2.25. Equivalency . . . . . . . . . . . . . 58

2.26. Some theorems of propositional logic . . . . . . . 60 
2.3. The algebra of classes . . . . . . . . . . . . 65

2.4. BooleAn algebra . . . . . . . . . . . . . . . . . 73

2.41. Application of Boolean algebra to switching networks 77

2.5. Further development and rounding-off of the foregoing theory 80

2.6. Semantic entailment according to E. W. BETH . . . . . . 86

2.61. Some definitions . . . . . . . . . . . . . . . . . 86

2.62. The fundamental task of logic . . . . . . . . . . . . 88

2.63. Some examples of semantic proofs . . . . . . . . . . . 90

2.631. First example. The syllogism BARBARA . . . . . 91

2.632. Second example. The syllogism DARAPTI . . . . 92

2.633. Third example. A very simple geometry . . . . . 93

2.64. Some final remarks . . . . . . . . . . . . . . . . 98

Chapter III: CODES AND LANGUAGES . . . . . . . . . . 101

3.1. General remarks . . . . . . . . . . . . . . . . . . 101

3.2. Codes and languages in general . . . . . . . . . . . 102

3.3. Examples of some codes . . . . . . . . . . . . . . . . 105

3.31. The binary number system considered as a code . . . . 105

3.32. The "excess-three" code . . . . . . . . . . . . . 107

3.33. The $m$-out-of- $n$-code . . . . . . . . . . . . . . . . 107

3.331. The 1-out-of-n code or linear code . . . . . . . 107

3.332. The 2-out-of-5 code . . . . . . . . . . . . . 107

3.333. The 3-out-of-7 code . . . . . . . . . . . . . 108

3.34. The international telegraph code No. 2 . . . . . . . . 108

3.4. Self-checking and self-correcting codes . . . . . . . . 110

3.5. Example of a language and its analysis . . . . . . . . . . 116

3.51. Introductory remarks . . . . . . . . . . . . 116

3.52. The structure of Carnap $n \pi$, . . . . . . . . . . . . 117

3.53. Example of a Carnap $n \pi$, . . . . . . . . . . . . . . 120

3.54. The concept of semantic information . . . . . . . . . 122

3.541. Some introductory remarks . . . . . . . . . . 122

3.542. CARnAP's definitions of information . . . . . . 124

Chapter IV: COMPONENT PARTS OF LOGICAL NETWORKS 131

4.1. Some introductory remarks . . . . . . . . . . . . . . . 131

4.2. The most important circuit elements . . . . . . . . . 133

4.21. The diode . . . . . . . . . . . . . . . . . . 134

4.22. The transistor . . . . . . . . . . . . . . 135

4.23. The magnetic core . . . . . . . . . . . . . . . . 141

4.231. Some general remarks . . . . . . . . . . . 141 
4.232. Magnetic memory cores . . . . . . . . . . . 144

4.233. Parasitic pulses . . . . . . . . . . . . . . . 147

4.234. Some mathematical considerations . . . . . . . 149

4.3. Some important basic circuits . . . . . . . . . . . . 154

4.31. The single-shot . . . . . . . . . . . . . . 154

4.32. The flip-flop . . . . . . . . . . . . . 158

4.33. The AND-gate and the oR-gate . . . . . . . . . . 161

4.34. The Not-gate or inverter . . . . . . . . . . . . . 162

4.35. Basic circuits using single-shots . . . . . . . . . 163

4.351. Shifting a pulse . . . . . . . . . . 163

4.352. Pulse gate which only passes pulses of phase $t_{1}$. . 164

4.353. The Not-gate . . . . . . . . . . . . 164

4.354. AND-gates and OR-gates . . . . . . . . . . . . 165

4.4. Some important larger units . . . . . . . . . . . . 165

4.41. Shift registers and counting circuits . . . . . . . 165

4.42. Selection circuits . . . . . . . . . . . . 172

4.421. The contact pyramid . . . . . . . . . . . 172

4.422. The coordinate selector . . . . . . . . . 173

4.43. Memories . . . . . . . . . . . . . 176

4.431. Introductory remarks . . . . . . . . . . . 176

4.432. Example of a permanent memory . . . . . . . 179

4.433. Examples of non-permanent memories . . . . 183

4.434. Some further particulars concerning magnetic cores 186

4.44. The signal transformer . . . . . . . . . . . . . . . 189

4.45. The self-adapting signal transformer . . . . . . . . 191

4.451. Some introductory remarks . . . . . . . . . . 191

4.452. WidRow and ANGELL's solution . . . . . . . . 193

4.453. Some mathematical considerations . . . . . . . 195

4.454. Another solution . . . . . . . . . . . . 200

4.46. The arithmetic unit of a digital electronic computer . . 203

4.461. Some preliminary remarks . . . . . . . . . 203

4.462. Principle of the construction of a binary adder . . 206

4.463. The HeYn adder . . . . . . . . . . . . . . . 210

4.47. Control circuit for a conditional program . . . . . . 215

4.471. Some general considerations . . . . . . . . . 215

4.472. SchiTz-Mol circuit . . . . . . . . . . . 220

Chapter V: MECHANISMS IN GENERAL . . . . . . . 225

5.1. Survey of the theory of linear differential equations . . . . . 225

5.11. Some general remarks . . . . . . . . . 225 
5.12. The homogeneous linear differential equation . . . . . 228

5.13. The case of constant coefficients . . . . . . . . . 231

5.131. The homogeneous linear differential equation with constant coefficients . . . . . . . . 231

5.132. Particular integral of the complete equation . . . 234

5.2. The LAPLACE transform . . . . . . . . . . . . . . . 236

5.21. Definition of the LAPLACE transform . . . . . . . . . 236

5.22. Some general properties of the LAPLACE transform . . . 240

5.23. Examples of LAPLACE transforms . . . . . . . . . . 243

5.231. The unit step function . . . . . . . . . . 243

5.232. The unit pulse function . . . . . . . . . . . . 246

5.24. The inversion problem for rational functions . . . . 250

5.3. Application of the transformation of LAPLACE to linear differential equations with constant coefficients . . . . . . . . 255

5.31. General integral of the reduced equation . . . . . . . 256

5.32. Particular integral of the complete equation . . . . . . 257

5.33. Behaviour of the integrals for very large values of $x$. . 261

5.34. Formulae for the particular integral of a linear differential equation . . . . . . . . . . . . . . 264

5.4. Basic principles of electric network theory . . . . . . . 268

5.41. Networks in general . . . . . . . . . . . . 268

5.411. Introductory remarks . . . . . . . . . . . 268

5.412. Equations governing the behaviour of a network . . 271

5.413. The electromagnetic energy excited by the currents

and voltages in a network. . . . . . . . . 273

5.42. The dipole . . . . . . . . . . . . . . 276

5.421. Solution of the equations governing the behaviour of

a dipole . . . . . . . . . . . 276

5.422. The reactive dipole . . . . . . . . . . . . . . . 278

5.423. The RC-circuit and the RL-circuit . . . . . . . 283

5.424. The response of a dipole to a voltage . . . . . . 286

5.43. The passive quadrupole . . . . . . . . . . . . 289

5.5. Principles of feedback theory . . . . . . . . . . . . . . . 299

5.51. Introductory remarks . . . . . . . . . . . . . . . 299

5.52. Feedback systems in general . . . . . . . . . . . 309

5.53. Some considerations based on function theory . . . . 311

5.6. Separation of message and noise . . . . . . . . . 317

5.61. Digital signalling . . . . . . . . . . . . . 317

5.62. Analogue signalling and the theory of KOLMOGOROFF and

WIENER ... . . . . . . . . . . . . 319 
5.63. A few critical final remarks . . . . . . . . . . . 324

5.7. Something about the digital computer . . . . . . . . . . 325

5.71. The block diagram of the digital computer . . . . . . 326

5.72. Example of a simple arithmetic program . . . . . . . 332

5.73. Example of a puzzle program . . . . . . . . . . 335

5.731. The puzzle and its analysis . . . . . . . . . . 335

5.732. Checking whether a symbol $\left(x_{\xi}, y_{\eta}, z_{\zeta}, \ldots\right)$ repre- 339 sents a solution or not . . . . . . . . . . . . 339

5.733. Determination of the successor of a symbol of the form $\left(x_{\xi}, y_{\eta}, z_{\zeta}, u_{\phi}, v_{\chi}, w_{\psi}, t_{\tau}\right) \ldots \ldots . . .344$

5.74. Example of a learning program . . . . . . . . . 345

5.741. A few introductory remarks . . . . . . . . . 345

5.742. OETTINGER's problem . . . . . . . . . . . . 346

5.743. Arithmetization of the problem . . . . . . . . . 346

APPENDIX A: HARMONIC FUNCTIONS AND THEIR COMPLEX REPRESENTATION . . . . . . . . . . . . . . . . 349

APPENDIX B: STOCHASTIC PROCESSES . . . . . . . . . 353

1. Introduction . . . . . . . . . . . . . . 353

2. A few concepts . . . . . . . . . . . . . . . . . 354

3. The statistical parameters . . . . . . . . . . . . 355

4. The stationary stochastic process . . . . . . . . . . . 359

5. Remarks about the definitions . . . . . . . . . . . . 361

6. Ensemble of equivalent processes. . . . . . . . . . . . . 362

7. The ergodic hypothesis . . . . . . . . . . . . . . . 362

8. The intercorrelation function of two stochastic series . . . . . 364

9. Stochastic independence . . . . . . . . . . . . . 365

APPENDIX C: FOURIER INTEGRALS AND SERIES . . . . 367

1. An important integral . . . . . . . . . . . . . . . 367

2. DiRICHLET's theorem . . . . . . . . . . . . . . . . . . . 369

3. FouRIER's integral . . . . . . . . . . . . . . . . . 370

4. BESSEL's theorem relating to trigonometric series . . . . . . . 372

5. Uniqueness of the expansion in a trigonometric series . . . . . 373

6. DiRICHLET's proof for the expandability in a trigonometric series 373

ALPHABETICAL INDEX . . . . . . . . . . . 375 


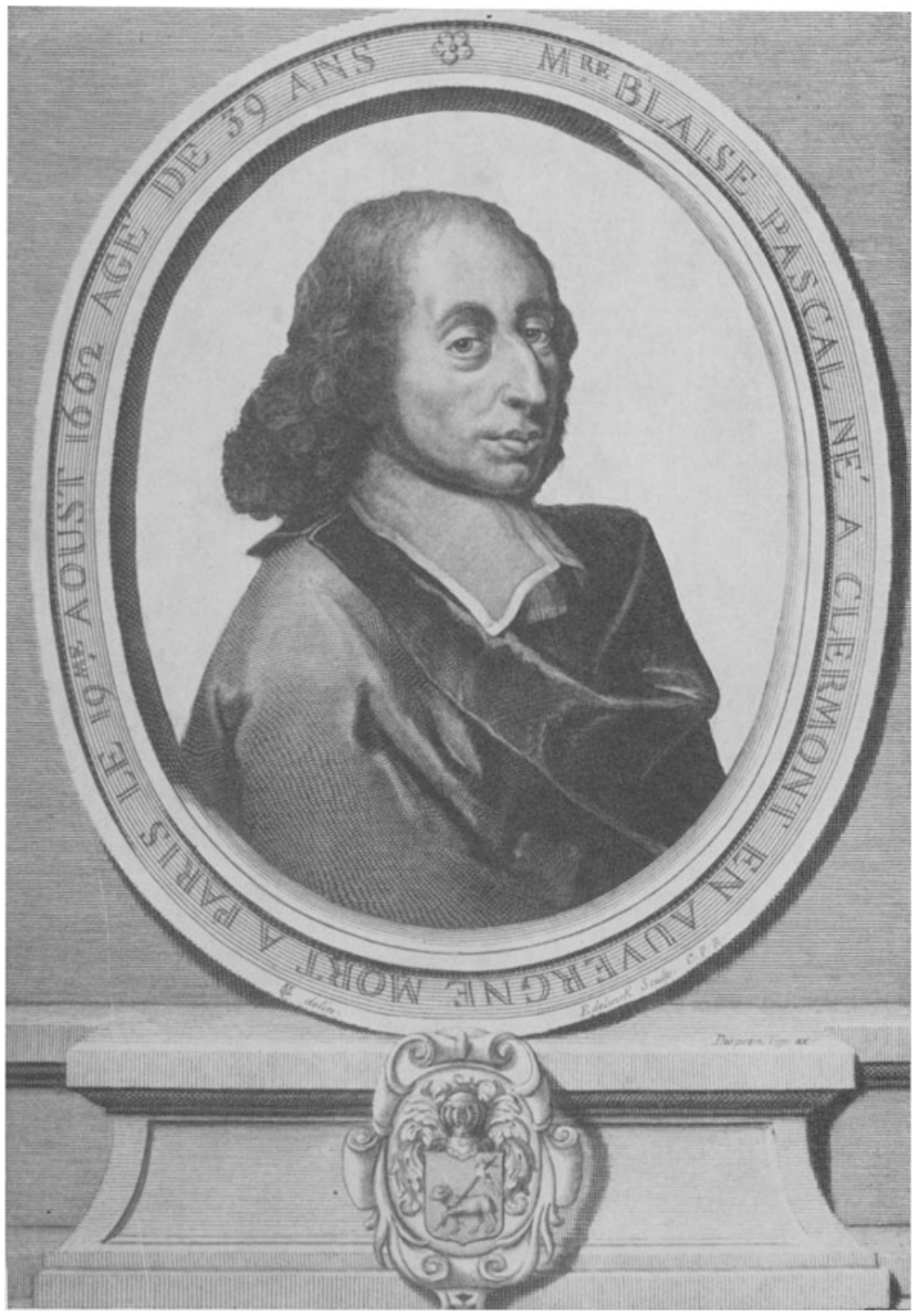

Copyright N.V. Uitgeversmaatschappij Elsevier, Amsterdam

\section{BLAISE PASCAL}


Not the very first, but certainly one of the most brilliant and famous designers of a computing machine (in fact only an adder and subtractor) was BLAISE PASCAL (1623-1662). In 1642 (or 1641, both dates are mentioned in the literature) he hit on the idea of constructing a computing machine to help his father (then in charge of the collection of taxes in ROUEN) in his work. Because of the backward state of engineering in Pascal's days, it was, however, impossible to construct from his drawings a machine which worked without error for a reasonable length of time. However, PASCAL does not owe his fame to this invention, but to his activity as a mathematician (PASCAL's theorem about conics, PASCAL's triangle, foundation of probability theory), physicist (foundation of hydrodynamics, PASCAL's law) and philosopher (Lettres Provinciales, Pensées de M. Pascal sur la religion). In particular his Pensées have had a lasting influence on French intellectual thought. 